DOI: 10.5604/01.3001.0013.2551

\title{
MATHEMATICAL MODELING OF THE PROCESS OF DRAWING AN OPTICAL FIBER USING THE LANGEVIN EQUATION
}

\author{
Aliya Tergeussizova \\ Al-Farabi Kazakh National University, Faculty of Information technology/Department Artificial intelligence and Big Date
}

Abstract. In order to design stochastic pulse frequency systems for automatic control of objects with delay, this article shows how we obtained their models in the form of stochastic differential equations. The method of dynamic compensation of objects with delay is considered. A stochastic differential system in the Langevin form is obtained.

Keywords: transport delay, object with delay, dynamic compensation method, Langevin differential equations

\section{MODELOWANIE MATEMATYCZNE PROCESU WYCIĄGANIA ŚWIATLOWODU WYKORZYSTUJĄCE RÓWNANIE LANGEVINA}

\begin{abstract}
Streszczenie. W celu zaprojektowania stochastycznych systemów impulsowych przeznaczonych do automatycznego sterowania obiektami z opóźnieniem pokazano, jak uzyskano te modele $w$ postaci stochastycznych równań różniczkowych. Rozważano metodę dynamicznej kompensacji obiektów z opóźnieniem. Uzyskano stochastyczny układ różnicowy w postaci Langevina.
\end{abstract}

Słowa kluczowe: opóźnienie transportu, opóźnienie obiektu, metoda kompensacji dynamicznej, równania różniczkowe Langevina

\section{Introduction}

As it is known, the optical fiber (OF) as a physical medium for the information transfer has a number of significant advantages in comparison with others, namely: a wide bandwidth and low signal attenuation provides the transmission of large amounts of information over long distances without the need for signal regeneration. The optical fiber is insensitive to electromagnetic fields, which prevents the occurrence of induced interference in the information transmission, fiber-optic communication lines have a much smaller volume and mass per unit of transmitted information than any thers.

The technological process of manufacturing the gradient optical fibers consists of two technological stages - the preform (parison) preparation of the parabolic profile from the core's refractive index and the subsequent drawing of the fiber from the preform.

The node in which the optical properties of the fiber are formed is a high-temperature furnace into which a billet is introduced, at the lower end of which a melt drop is formed-the pulling zone (bulb).

The specified optical properties of the fiber, including the attenuation coefficient, are achieved by a particular hood regime. According to the results of measuring the parameters of a specific preform, the individual values of the extract's main regime parameters are determined for the pulling speed $-v_{T}$ and the pulling tension $-F_{0}$, the combination of which provides the optimal shape of the constriction zone at the end of the preform, which determines the given optical characteristics of the finished fiber. The hood tension is the tension force of the fiber $F_{0}$, between the constriction zone and with a primary lacquer coating. In the production of optical fibers and in the relevant production documentation, the hood tension is taken to be measured and normalized in grammaxiles (gf), and not in SI units.

The purpose of the projected automation system control is the temperature control of the high temperature furnace $(\mathrm{HTF})-\mathrm{T}_{\mathrm{HTF}}$, which determines the hood tension at a known speed, and the drives control of the preform and traction wheel feeding device, which determines the preform feed rate $-v_{n}$ and the hood speed $v_{T}$. In this case, the control algorithm of the drawing process must provide a given combination of tension and hood speed with the existing disturbing influences [10-16].

\section{Research model}

The construction of an automatic control system for the tension hood and fiber diameter, in its turn, requires the construction of adequate models of the controlled object. As a control object, a nozzle zone is considered in the work, in which the tension and fiber diameter are formed. Namely, the control action (the temperature of the high temperature furnace $-\mathrm{T}_{\mathrm{HTF}}$ ) enters the input of a nonlinear static inertia-free substructure, the output effect of which is transformed by a linear inertial substructure. Physically, the nonlinear characteristic can be explained by the nonlinear dependence of the surface tension of the nozzle zone on its temperature. A linear non-rationality can be explained by the fact that when changing to a different temperature of the furnace, the volume of the hood zone changes smoothly.

Figure 1 shows the block diagram for controlling the fiber hood system, which contains a loop for automatically controlling the fiber diameter and hood tension [9].

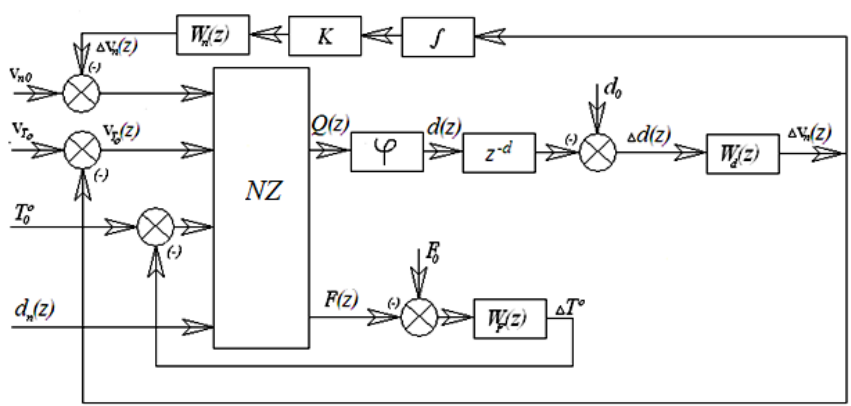

Fig. 1. The block diagram of the fiber process control system

In Figure 1: NZ - nozzle zone; $\mathrm{d}$ - the delay is equal to the time of motion from the hooded fiber diameter for the bulb to the sensor; $\mathrm{W}_{\mathrm{n}}(\mathrm{z})$ - is the digital regulator of the preform feed rate; $\mathrm{W}_{\mathrm{F}}(\mathrm{z})$ - The digital tension control for the hood; $\mathrm{W}_{\mathrm{d}}(\mathrm{z})$ - is a digital fiber diameter regulator; $\mathrm{K}$ - is the coefficient of proportionality between the fiber sections and the preform; $\varphi$ - is the static coefficient reflecting the relationship between the fiber diameter and the melt flow coming from the bulb. 
Another important task is to increase the dynamic accuracy of regulation. The low dynamic accuracy of regulation is due to the inertia of the regulated object and the so-called "transport delay". The latter is determined by the time of passage of the extracted glassware from the formation zone to the sensor determining the dimensions of the cross section. As a result, self-oscillations may appear.

To solve the problem of temperature control, the most promising activity will be the use of dynamic frequency-pulse systems for automatic control of objects with delay. Control systems of this class are characterized by the presence of nonlinear transformations of signals, as well as parametric feedbacks [4].

In the present work, a frequency-pulse stabilization system (FPSS) is considered for the temperature of a high-temperature extraction furnace for an optical fiber.

FPSS temperature of high-temperature hood furnace for the optical fiber is a closed system consisting of $\Sigma$-FPS and the reduced continuous part (RCP), its block diagram is shown in figure $2[5]$.

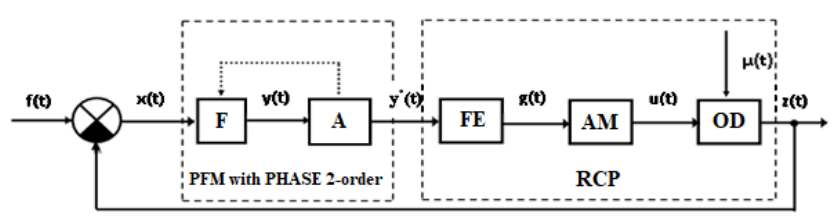

Fig. 2. Structural diagram of $\Sigma$ - FPSS

At the input of the system, there is a stationary random process $f(t)$. The reduced continuous part - RCP consists of a series connection of the controlled object with delay - OD, an actuating mechanism (AM), and a forming element (FE), which defines the desired shape of the control pulses. In the general case, RCP is characterized as a nonlinear dynamical system with random parameters and is represented by some functional equation of the following form:

$$
z(t)=H\left[\lambda, \tau_{0}, z(\tau), g(\tau) / t_{0} \leq \tau \leq t\right]
$$

where $\mathrm{H}$ is a continuous non-linear functional; the parameter characterizes the randomness of the functional parameters $\mathrm{H}$; $\mathrm{g}(\mathrm{t})$ is a sequence of control random pulses of a given shape; $\tau_{0}$ - is the delay time of the controlled object.

The motion equation of the $\Sigma$ - frequency-pulse modulator consists of the motion equation of the filter $F$ and the equations determining the moments of appearance and the sign of the pulses, and the operations of resetting.

$\Sigma$-FPM of the second order is a serial connection of a filter realized as a 2-order aperiodic link and an impulse device of the ID.

A filter realized as an aperiodic link of the first order is described by the following transfer function:

$$
D(p)=\frac{k_{\phi}}{p+\alpha_{\phi}}
$$

where $k_{\phi}$ is the gain coefficient of the aperiodic link of 1 -order, and $\alpha_{\phi}$-is the time of inertia.

In this paper, as a control object, the waist zone is considered, in which both tension and fiber diameter are formed. Experimental studies of the extraction process in various modes allow us to determine that the object has a second-order degree, the static transfer coefficient has nonlinearity, and the object also has a transport time delay due to the distance from the waist area to the diameter sensor. The continuous transfer function of the waist zone depends on the temperature of the waist zone and the temperature in the high-temperature furnace. These findings allow us to describe mathematically the dependence of fiber diameter on temperature in a high-temperature furnace in the form of a continuous transfer function of the form [11]:

$$
W_{L}(p)=\frac{T_{L}(p)}{T_{H T F}(p)}=\frac{e^{-p \tau_{L}}}{\left(1+T_{1} p\right)\left(1+T_{2} p\right)}
$$

where, $\mathrm{T}_{1}-$ is the time constant determined by the hydrodynamic properties of the waist zone; $\mathrm{T}_{2}-$ is the time constant, which determines the heating time of the waist area; $\tau_{L}$ - lag time, determined by the length of the waist area, $\mathrm{T}_{\mathrm{L}}$ - the temperature of the waist area.

$$
\begin{gathered}
W_{L}(p)=\frac{T_{L}(p)}{T_{H T F}(p)}=\frac{e^{-p \tau_{L}}}{\left(1+T_{1} p\right)\left(1+T_{2} p\right)}=\frac{e^{-p \tau_{L}}}{T_{1} T_{2} p^{2}+\left(T_{1}+T_{2}\right) p+1}= \\
=\frac{e^{-p \tau_{L}}}{T_{1} T_{2}\left(p^{2}+\frac{T_{1}+T_{2}}{T_{1} T_{2}} p+\frac{1}{T_{1} T_{2}}\right)} \\
K_{1}=\frac{1}{T_{1} T_{2}}, L_{1}=\frac{1}{T_{1} T_{2}}, L_{2}=\frac{T_{1}+T_{2}}{T_{1} T_{2}}
\end{gathered}
$$

The main channels for controlling the parameters of the temperature mode of an optical fiber drawing process, taking into account the transfer functions of the actuator - AM and the formbuilding element - FE with an acceptable accuracy, the transfer function (1) is represented by a transfer function of the form [1]:

$$
\begin{gathered}
W_{L}(p)=\frac{K_{1} e^{-p \tau_{L}}}{p^{2}+L_{2} p+L_{1}} \\
W_{L}(p)=\frac{x_{2}}{u}=\frac{K_{1} e^{-p \tau_{L}}}{p^{2}+L_{2} p+L_{1}}
\end{gathered}
$$

As a control algorithm in this system, the $\Sigma$-FPM algorithm is used, the filter in this algorithm is the main control element defining the control pulse.

\section{Construction of the mathematical model}

In order to design stochastic pulse frequency systems for automatic control of objects with delay, one should first of all get their models in the form of stochastic differential equations. Equivalent and majorization systems can be used for this purpose. Describing them directly, one can obtain stochastic differential equations in the form of Langevin. Then they should be converted to Ito form. Consider the construction of mathematical models of the subsystem of direct digital control (DDC) control parameters of the temperature process of drawing optical fiber. According to Figure 3, this system is described by the following equations [6]:

$$
\begin{gathered}
x(t)=x_{2}(t)-z(t) \\
x_{2}^{(2)}+L_{2} x_{2}^{(1)}+L_{1} x_{2}=u K_{1} e^{-p \tau_{L}} \\
\mathrm{z}(\mathrm{t})=\vec{q}_{0}^{T} \vec{z}\left(t-\tau_{L}\right) \\
y_{v}(t)+\left[\alpha_{\phi}+s(t)\right] y_{v}(t)=k_{\phi} x\left(t-\tau_{m}\right) \\
\mathrm{u}(\mathrm{t})=\varphi\left[\frac{y_{v}(t)}{\Delta}\right]
\end{gathered}
$$

where, $k_{\phi}-$ is the filter gain factor $\sum$-FPM, $\Delta-$ is the threshold value of the pulse device of the PD; $\tau \mathrm{m}-$ is the modulator modification parameter.

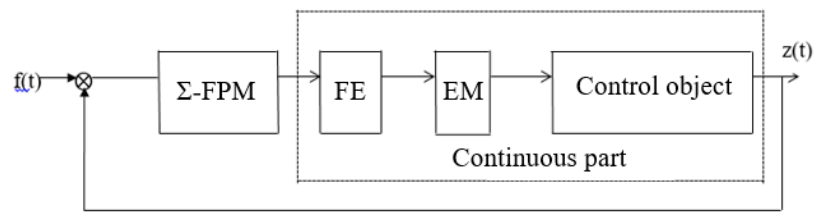

Fig. 3. Block diagram of the control circuit control parameters of the temperature regime of the process of drawing optical fiber

The continuous part of the system containing the control object with delay is described by differential - difference equations of the form [8]:

$$
\begin{gathered}
\dot{\vec{z}}(t)=\overrightarrow{A_{0}} \vec{z}(t)+\overrightarrow{C_{0}} u(t) \\
z(t)=\overrightarrow{B_{0}^{T}} \vec{z}\left(t-\tau_{0}\right)
\end{gathered}
$$

where, $0<\tau_{0}<\infty$ the lag time of the control object, $\overrightarrow{A_{0}}, \overrightarrow{B_{0}^{T}}$ and $\overrightarrow{C_{0}}$ are respectively real constants of $\mathrm{n} \times \mathrm{n}, \mathrm{n} \times 1, \mathrm{~m} \times \mathrm{n}$ matrices.

$$
\left[\begin{array}{l}
\ddot{x}_{1} \\
\ddot{x}_{2}
\end{array}\right]=[A],\left[\begin{array}{l}
\dot{x}_{1} \\
\dot{x}_{2}
\end{array}\right]+[B] u,\left\{\begin{array}{c}
x=A x+B u \\
y=C x
\end{array}\right.
$$

To reduce the differential order, we make the assumption that:

We get:

$$
\begin{gathered}
\dot{x}_{1}=x_{2} \rightarrow \ddot{x}_{1}=\dot{x}_{2} \\
{\left[\begin{array}{l}
\ddot{x}_{1} \\
\ddot{x}_{2}
\end{array}\right]=\left[\begin{array}{cc}
0 & 1 \\
-L_{1} & -L_{2}
\end{array}\right],\left[\begin{array}{l}
\dot{x}_{1} \\
\dot{x}_{2}
\end{array}\right]+\left[\begin{array}{c}
0 \\
K_{1}
\end{array}\right] u}
\end{gathered}
$$

$$
\overrightarrow{\mathrm{A}_{0}}=\left[\begin{array}{cc}
0 & 1 \\
-L_{1} & -L_{2}
\end{array}\right], \overrightarrow{B_{0}}\left[\begin{array}{c}
0 \\
K_{1}
\end{array}\right], \overrightarrow{C_{0}}=\left[\begin{array}{ll}
1 & 0
\end{array}\right]
$$

respectively, matrices of dimensions $(2 \times 2),(2 \times 1)$ and $(1 \times 2)$. 


\subsection{Dynamic compensation method of delays in an object}

The drawing tower of an optical fiber, or rather, the waist area, is an object having a time delay in the measurement channels, which functions according to (10) and (11). The principle of one of the approaches to the design of regulators for such objects is to apply the method of dynamic compensation of delays in the object [7].

Since in our object only the signals in the measurement channels are late, i.e. $\mathrm{T}=0$, then the equation of the dynamics of the object will take the form:

$$
\begin{gathered}
H: \dot{x}(t)=A x(t)+B_{0} u(t)+f(t) \\
y(t) \sum_{L=0}^{i} C_{L} x\left(t-\tau_{L}\right)+\eta(t)
\end{gathered}
$$

Along with our object, we consider a device whose input is given by a signal $\mathrm{u}(\mathrm{t})$, which is the input control for object $\mathrm{H}$, and which functions according to the equations:

$$
\begin{gathered}
K: \dot{\mu}(t)=A \mu(t)+B_{0} u(t) \\
\delta y(t)=R \mu(t)-\sum_{L=0}^{i} C_{L} x\left(t-\tau_{L}\right)
\end{gathered}
$$

where $t \epsilon R, \mu \epsilon R^{n}$ - is the phase vector of the device, $\delta y(t) \epsilon R^{m}$ is its output. The constant real matrix $R$ is determined by the equality:

$$
R=\sum_{L=0}^{i} C_{L} \exp \left(-A \tau_{L}\right)
$$

Next, we consider the composite system $\mathrm{H}^{*} \mathrm{~K}$ with the control input $\mathrm{u}(\mathrm{t})$ and the output $y_{k}(t)$ formed according to the parallel connection of the device $\mathrm{K}$ to the object $\mathrm{H}$.

$$
y_{k}(t)=y(t)+\delta y(t)
$$

The following argue that the correction device $\mathrm{K}$ allows you to compensate for the delay in the object $\mathrm{H}$.

The behavior of the composite system $\mathrm{H}^{*} \mathrm{~K}$, functioning according to equations (11) and (15), obeys the equations:

$$
\begin{gathered}
H_{k}: \dot{x}(t)=A x(t)+B_{0} u(t)+f(t) \\
y_{k}(t)=R x(t)+\eta_{k}(t)
\end{gathered}
$$

where, $t \in R$, and $\eta_{k}(t) \in R^{m}$ depends only on disturbing influences:

$$
\eta_{k}(t)=\eta(t)-\sum_{L=0}^{i} C_{L} \int_{0}^{L} \exp \left(A\left(\theta-\tau_{L}\right)\right) f(t-\theta) d \theta
$$

Proof: Subtracting (13) from (16), you can get:

$$
d\left(x(t)-\frac{\mu(t)}{d t}=A(x(t)-\mu(t))+f(t)\right.
$$

From here, according to the Cauchy formula, we get:

$$
x(t)-\mu(t)=
$$

$\exp \left(A \tau_{L}\right)\left(x\left(t-\tau_{L}\right)-\mu\left(t-\tau_{L}\right)\right)+\int_{0}^{L} \exp (A \theta) f(t-\theta) d \theta$

Multiply this equality on the left by $C_{L} \exp \left(-A \tau_{L}\right)$, setting $L=0,1, \ldots, 1$ and performing summation over this index, we get:

$$
\begin{gathered}
\sum_{L=0}^{i} C_{L} \exp \left(-A \tau_{L}\right) x(t)-\sum_{L=0}^{i} C_{L} \exp \left(-A \tau_{L}\right) \mu(t)= \\
\sum_{L=0}^{i} C_{L} x\left(t-\tau_{L}\right)-\sum_{L=0}^{i} C_{L} \mu\left(t-\tau_{L}\right)+ \\
\sum_{L=0}^{i} C_{L} \int_{0}^{L} \exp \left(A\left(\theta-\tau_{L}\right)\right) f(t-\theta) d \theta
\end{gathered}
$$

From this equality, taking into account (19) and relations (15), (16) and (13), it is easy to obtain (18).

Thus, the corrective device $\mathrm{K}$ is a dynamic compensator for delays in the object $\mathrm{N}$, figure 4 .

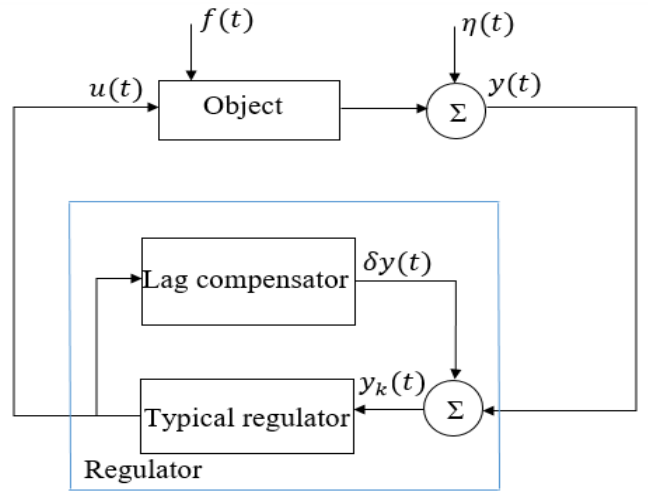

Fig. 4. Block diagram of the regulation system realizes the principle of dynamic compensation for delays
The system $H_{k}$, functioning according to equations (17) and (18), which, in essence, is a completely manageable and identifiable part of the component system $\mathrm{H}^{*} \mathrm{~K}$, will be called a compensated object. Since the compensated object is a finitedimensional dynamic system, its state can be regulated by means of a typical regulator.

So, if we first compensate for delays in the object, and then adjust the state of our compensated object with a typical regulator, the latter will ultimately regulate the state in the control object $\mathrm{N}$. The block diagram of the regulation system that implements this principle is presented in Figure 2, and the controlled movement of the control object itself will be described by the functional diagram presented in Figure 5 .

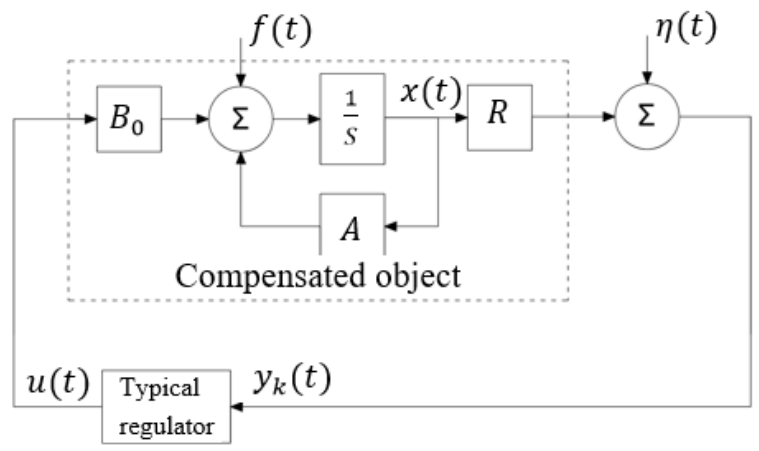

Fig. 5. Type of adjustable movement

According to, considered, method of dynamic compensation of delays, our object with delay, functioning according to (10) and (11) can be represented as follows [6]:

$$
\begin{gathered}
\overrightarrow{\mathrm{z}}(\mathrm{t})=\overrightarrow{\mathrm{A}_{0}} \overrightarrow{\mathrm{z}}(\mathrm{t})+\overrightarrow{\mathrm{C}_{0}} \mathrm{u}(\mathrm{t}) \\
\mathrm{z}(\mathrm{t})=\overrightarrow{\mathrm{B}_{1}^{\mathrm{T}}} \overrightarrow{\mathrm{z}}(\mathrm{t})
\end{gathered}
$$

where, $\overrightarrow{\mathrm{B}_{1}^{\mathrm{T}}}=\overrightarrow{\mathrm{B}_{0}^{\mathrm{T}}} \exp \left(-\overrightarrow{A_{0}} \tau_{L}\right)-$ the fundamental matrix of the system with the value $\mathrm{t}=-\tau_{L}$.

\subsection{Differential equations of Langevin}

Combining the RCP (educed continuous part) equation (12) and the modified $\Sigma$-FPM (8) - (9), we obtain the stochastic differential system in the Langevin form [14 - 16]:

$$
\begin{gathered}
\overrightarrow{\mathrm{z}}(\mathrm{t})=\overrightarrow{A_{0}} \overrightarrow{\mathrm{z}}(\mathrm{t})+\overrightarrow{C_{0}} u(t)+\vec{D}_{0}[\vec{z}] \vec{\mu}(t) \\
z(t)=\vec{L}_{1}^{T} \vec{z}(t), u(t)=\varphi\left[\frac{\mathrm{y}_{\mathrm{v}(\mathrm{t})}}{\Delta}\right] \\
y_{v}(t)=\alpha_{\phi} y_{v}(t)-k_{\phi} \vec{q}_{0}^{T} \tau_{0} \vec{z}(t)+N_{0}\left[y_{v}(t)\right] s(t)
\end{gathered}
$$

where

$$
\begin{gathered}
\overrightarrow{\mathrm{z}}(\mathrm{t})=\left[z_{1} z_{2}\right]^{T} \quad \vec{\mu}(t)=\left[\mu_{1} \mu_{2}\right]^{T} \\
\overrightarrow{\mathrm{D}_{0}} \overrightarrow{\mathrm{z}]}=\left[\begin{array}{cc}
0 & 0 \\
-z_{1} & -z_{2}
\end{array}\right] \\
N_{0}\left[y_{v}(t)\right]=-y_{v} \\
\vec{q}_{0}^{T} \tau_{0}=\vec{q}_{0}^{T}\left\{\exp \left(-\overrightarrow{A_{0}} \vec{\tau}_{0}\right)-\left[\exp \left(-\overrightarrow{A_{0}} \vec{\tau}_{m}\right)-\vec{I}\right]\right\}
\end{gathered}
$$

$\vec{I}$ - dimension unit matrix $(2 * 2)$.

\section{Conclusion}

An approach to the construction of mathematical stochastic sigma frequency - pulse systems of automatic control of objects with delay is proposed. For the mathematical model of the sigma frequency - pulse control system for objects with delay in the form of stochastic differential equations, a procedure for their construction, based on the equivalent and majorising systems, is proposed. We obtain stochastic differential equations in the Langevin form. 


\section{References}

[1] Aitchanov B.H., Aitchanova Sh.K., Baimuratov O.A., Aldibekova A.N A Simplified Model of the Control System with PFM. XII International Conference on Information Technology and Engineerin. 17(5)/2015, 14651468 .

[2] Aitchanov B.H., Aldibekova A.N.: Primenenie dinamicheskogo chastotnoimpulsnogo modulyatora $\mathrm{v}$ sistemah upravleniya $\mathrm{s}$ ispolzovaniem yadernogo magnitnogo rezonansa $\mathrm{v}$ ustroystvah omagnichivaniya zhidkostey. Vestnik KazNTU.

[3] Aitchanov B.H., Baimuratov O.A., Aldibekova A.N.: Pulse - Frequency control system of the fluids magnetization of the used nulear magnetic resonance. The 2nd International Virtual Conference on Advanced Scientific Results (SCIECONF - 2014), 473-477.

[4] Aitchanov B.H., Tergeusizova A.S.: Tehnologicheskij process vytjazhki opticheskih sterzhnej kak objekt avtomatizirovannogo upravlenija. Doklady Nacional'noj akademii nauk Respubliki Kazahstan 2/2017, 91-95.

[5] Aitchanov B.H.: Metody matematicheskogo opisanija chastotno-impulsnyh sistem upravlenija obektami s zapazdyvaniem. Vestnik KazNTU 2(30)/2002, $72-82$.

[6] Aitchanov B.H.: Time-domain quantization in dynamic pulse-frequency systems with transport delay. Poisk, Natural and technical sciences series, 209-214.

[7] Aitzhanov B.Kh., Kurmanov B.K., Umarov T.F.: Dynamic Pulse Frequency Modulation in Objects Control with Delay. Asian Journal of Control 14(6)/2012 $1662-1668$.

[8] Aitzhanov B.Kh., Nikulin V.V., Baimuratov O.A.: Mathematical Modeling of Digital Pulse-Frequency Modulation Control Systems Developed for Objects with Transport Delay. The Chinese Control and Decision Conference 2013, 1407-1411.

[9] Chostkovskij D.B.: Strukturnyj sintez sistemy upravlenija processom vytjazhki gradientnyh opticheskih volokon. Vestnik SamGTU. Serija Tehnicheskie nauki 4(27)/2010, 73-78.
[10] Friman R.: Volokonno-opticheskie sistemy svjazi. Tehnosfera, Moscow 2003

[11] http://oplib.ru - Open Library - Open library of educational information (available 15.05.2019)

[12] Listvin A.V., Listvin V.N., Shvyrkov D.V.: Opticheskie volokna dla liniy sviazi. LESARart, Moscow 2003.

[13] Roy P., et al.: Active Optical Fibers: New design and alternative method of fabrication. Photonics, Dehli 2008.

[14] Sandoz F., et al.: A Novel process to manufacture high efficiency laser fibers. Photonics, Dehli 2008.

[15] Sarkar A., Orchanian B., Chan A.: A Novel VAD process. Proceedings of the International Wire \& Cable Symposium, Providence 2008.

[16] Zhiro A.: Tehnologii proizvodstva opticheskih volokon. Obzor poslednih razrabotok. Nauka i tehnika 4/2009, 22-27.

\section{M.Sc. Eng. Aliya Tergeussizova}

e-mail: aliya55@mail.ru

Ph.D. student of the Faculty of Information Technology of the Al-Farabi Kazakh National University. Scientific research in the field of model development and research of the temperature control system for drawing optical fiber.

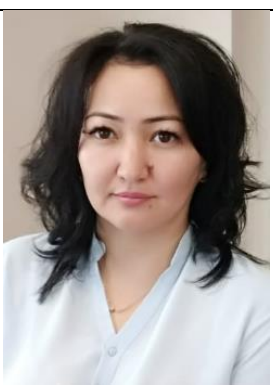

otrzymano/received: 15.05 .2019 